\title{
Spatial structure of recruitment in the mussel Perna perna at local scales: effects of adults, algae and recruit size
}

\author{
Johan Erlandsson, Christopher D. McQuaid* \\ Coastal Research Group, Department of Zoology \& Entomology, Rhodes University, Grahamstown 6140, South Africa
}

\begin{abstract}
To test the assumption that there is no spatial structure in small-scale recruitment variability of rocky shore mussels, we examined spatial dependence in the distribution of density of recruits (late plantigrades: 0.5 to $3.5 \mathrm{~mm}$; larger recruits: 3.5 to $10 \mathrm{~mm}$ ) and adults of the brown mussel Perna perna within local scales (30 lags ranging between 0.35 and $10.5 \mathrm{~m}$ ) in mid- and upper mussel beds. Spatial heterogeneity was estimated by analyzing scaling properties of semivariograms using a fractal approach. Relationships between density of mussel recruits and adults and biomass of the red alga Gelidium pristoides at the different scales were examined by cross-semivariograms. We found that the distribution of adults showed spatial dependence at all transects, often with higher spatial heterogeneity (higher fractal dimension, $D$ ) at smaller scales (1st scaling region). The distribution of larger recruits exhibited spatial dependence at all transects, revealing a spatial structure, which was related to that of adults. In contrast, the distribution of late plantigrades showed mainly spatial independence (random pattern; $1.97<D \leq 2$ ). Densities of both size classes of recruits were positively related to those of adults at all transects and scales, but the relationship was stronger for larger recruits than late plantigrades, explaining why there was clearer spatial structure of larger recruits. The relationship with algae was mainly negative for larger recruits, while it tended to be positive at many scales for late plantigrades. Thus, both adult mussels and G. pristoides are suitable habitats for plantigrades, while mussels are the main habitat for larger recruits. This may mean that recruits on algae either die or migrate to mussel clumps at a certain size. This study highlights the importance of recruit size when analyzing recruitment patchiness of mussels, and has implications for sustainable management of $P$. perna.
\end{abstract}

KEY WORDS: Recruitment heterogeneity - Intertidal mussel distribution - South Africa - Fractal dimension $\cdot$ Spatial dependence $\cdot$ Multi-scaling patchiness

\section{INTRODUCTION}

The abundance of mussels can vary significantly at regional scales (Suchanek 1985, Harris et al. 1998), meso-scales (McKindsey \& Bourget 2000, McQuaid et al. 2000), and local scales (Harris et al. 1998, Blanchard \& Bourget 1999, Lawrie \& McQuaid 2001). Intertidal mussel distribution may be very patchy at local withinshore scales, a phenomenon that has usually been studied at only 1 or 2 local scales simultaneously. At local scales, distribution often shows high, unpredictable variability compared to meso- and regional scales (e.g. Harris et al. 1998, Blanchard \& Bourget 1999, Lawrie \& McQuaid 2001). This is usually taken as evidence of an inconsistent and unstructured patchy pattern. However, other studies of intertidal mussel distribution over a wide range of continuous local scales have found that there is often spatial structure in the variability, with higher spatial heterogeneity at smaller local scales (Kostylev 1996, Kostylev \& Erlandsson 2001, J. Erlandsson unpubl. data).

While variability is a general term indicating changes in the value of a variable, heterogeneity indicates structure in variability across different scales, corre- 
sponding to aggregated (patchy or clumped) spatial distribution (Kolasa \& Rollo 1991, Ettema \& Wardle 2002). Spatial dependence is a concept dealing with the similarity between data points as a function of spatial separation (lag) between them, and can be thought of as the tendency for objects located close together in space to have similar values, exhibiting positive or negative autocorrelation (Legendre 1993, Ettema \& Wardle 2002). In the present study, we refer to spatial structure in the distribution of a variable, meaning that there is spatial dependence. Since spatial independence is a basic assumption in many standard statistical tests, and spatial dependence has often been detected in the rare cases when it has been examined in ecological systems (Palmer 1988, Wiens 1989), the importance of studies at a range of scales becomes apparent. Nested heterogeneity, i.e. multiple scales of patchiness, may occur because factors or processes influencing patterns operate and interact at different spatial scales (Wiens 1989, Sugihara \& May 1990). For example, the distribution of Mytilus edulis in softbottom mussel beds in Sweden had 2 or 3 natural scaling regions, mussels being aggregated into small local patches, which were in turn integrated into larger patches, etc. (Kostylev \& Erlandsson 2001).

It has been suggested that patch sizes of mussels on hard substrata are maintained by a balance of 3 general processes: recruitment, mortality and growth (Petraitis 1995). On rocky shores in southern Africa, the abundance of adult mussels and recruits varies substantially at a regional scale. The west coast, which is dominated by the invasive blue mussel Mytilus galloprovincialis, has densities of recruits and adults about 4 times higher than the south and east coasts, where the indigenous brown mussel Perna perna dominates (Harris et al. 1998). This variability can be explained by biogeographic differences in species composition, growth rates, spawning intensities, productivity, and by oceanographic and hydrodynamic conditions. At meso-scales on the southeast coast of South Africa (the area sampled in the present study), there is predictable variability in the abundance of adults, juveniles and recruits of $P$. perna between mussel beds separated by 100 s of meters (Lawrie \& McQuaid 2001); wave-exposed shores exhibit higher mortality rates and growth rates, and larger sizes of mussels than sheltered shores (McQuaid \& Lindsay 2000, McQuaid et al. 2000). However, at 2 local, within-shore scales, large unpredictable variability occurs, especially in recruitment (Lawrie \& McQuaid 2001). Subsequently it has been found that variability in the cover of $P$. perna shows clear spatial structure (i.e. spatial dependence) across a range of withinshore local scales, if there is spatial dependence in the distribution of topographic features (gullies, crevices, rock slope and aspect; J. Erlandsson unpubl. data). Within all these local scales there are also strong negative relationships between $P$. perna and the red alga Gelidium pristoides (J. Erlandsson unpubl. data).

Most marine invertebrates exhibit a pelagic larval stage in their life cycle, with pelagic dispersal and larval settlement being very important processes. While settlement is a discrete event that can be clearly defined biologically, recruitment of intertidal invertebrates may be operationally defined as entry into the benthic population of recruits up to the point at which dramatic post-settlement mortality ceases, i.e. the survivorship curve stabilizes (Booth \& Brosnan 1995, Caley et al. 1996). Following this definition, the recruitment process encompasses pre-settlement mortality, as well as settlement-associated and post-settlement mortality. The term recruits is then reserved for individuals surviving the stage of high settlementassociated mortality (Booth \& Brosnan 1995). In Perna perna, recruits are usually referred to as individuals between 0.5 and $10 \mathrm{~mm}$ in length, with early plantigrades (settlers) being $<0.5 \mathrm{~mm}$ in length and late plantigrades between 0.5 and $3.5 \mathrm{~mm}$ (Lasiak \& Barnard 1995, Harris et al. 1998, Lawrie \& McQuaid 2001).

Bayne (1964) found evidence that larvae of Mytilus edulis primarily settle onto filamentous algae, and then secondarily settle/recruit onto adult mussels after a period of growth and a secondary pelagic phase (termed the bysso-pelagic phase). Some studies support this finding (e.g. Seed 1969), but others have found that $M$. edulis larvae may settle directly onto adult mussels (e.g. McGrath et al. 1988), thus rejecting the primary/secondary settlement hypothesis for some populations. Lasiak \& Barnard (1995), working on the east coast of South Africa (Transkei), rejected the primary/secondary settlement hypothesis for Perna perna on those shores because densities of early plantigrades did not differ between filamentous algae and mussel clumps, and size distributions of settlers/recruits were usually the same on the 2 substrata. Gelidium pristoides is a common substratum for plantigrades of P. perna (Beckley 1979) and is abundant in the midand upper P. perna zones (McQuaid et al. 2000). Although Lindsay (1998) found that plantigrades were common among both algae and mussels, there were higher densities of both early and late plantigrades among algae, including $G$. pristoides, than among adult mussels.

In some bivalve species, recruit and adult densities tend to be associated with each other, although predictability is often low (Nielsen \& Franz 1995, Harris et al. 1998, Chiba \& Noda 2000, McQuaid et al. 2000) and adults may also inhibit recruitment (e.g. André et al. 1993). The association of recruits and adults may be 
due to larval choice during settlement and/or increased rates of survival for recruits settling among adults. Recruitment may, in turn, play a role in determining population structure of benthic organisms (Booth \& Brosnan 1995, Caley et al. 1996). Since recruit and adult densities are very low on the southeast coast of South Africa (compared to the west coast) and free space is common within mussel beds here, and since $P$. perna generally shows relatively low recruitment rates and slow recovery, these populations are likely to be recruitment limited (Lasiak \& Barnard 1995, Harris et al. 1998, McQuaid et al. 2000).

The present study posed the following hypotheses: (1) the high spatial variability in Perna perna recruitment at local within-shore scales exhibits spatial structure; (2) this spatial structure is related to the distributions of adult/subadult mussels and the alga Gelidium pristoides; (3) multiple scaling regions exist in the spatial heterogeneity of $P$. perna recruitment; (4) spatial structure is different between late plantigrades and larger recruits of $P$. perna, and is related differently to the spatial structure of adults/subadults; (5) relationships to adult/subadult mussels and to algae at a range of local scales are different for late plantigrades and larger recruits.

\section{MATERIALS AND METHODS}

Study area and sampling design. Intertidal mussel beds on the southeast coast of South Africa are 20 to $25 \mathrm{~m}$ long, and extend from just above the subtidal fringe to the low shore. These beds are monolayered, with the byssus threads of adults attached directly to the rock surface (McQuaid et al. 2000), and can be clearly divided into mid, low and upper zones within which mussel densities and sizes differ. Shores in this area are all wave exposed, and wave action can be very strong, sometimes dislodging substantial mussel patches (J. Erlandsson pers. obs.).

The spatial heterogeneity in the density of Perna perna recruits (0.51 to $10 \mathrm{~mm}$ in length) and adults/ subadults ( $>10 \mathrm{~mm}$; from here on referred to as adults) was studied on 3 sandstone shores (Waterloo Bay, Riet Point and Port Alfred: $33^{\circ} \mathrm{S}, 27^{\circ} \mathrm{E}$ ), 15 to $20 \mathrm{~km}$ apart. The mid-mussel zones at all 3 sites and the upper mussel zones at Riet Point and Port Alfred (upper zone of Waterloo Bay was sand inundated) were sampled along $21 \mathrm{~m}$ horizontal transects (1 transect per zone at each site). Sampling was done from April to June 2000 when recruitment was expected to be high (Beckley 1979, Lasiak \& Barnard 1995, Harris et al. 1998). We sampled 60 quadrats, measuring $10 \times 10 \mathrm{~cm}$, separated by $35 \mathrm{~cm}$ (measured between centers of quadrats) per transect. Mussels and algae in each quadrat were removed, and we searched carefully for small recruits in crevices using forceps. The samples were brought to the laboratory and frozen at $-12^{\circ} \mathrm{C}$ until processing. Mussels (especially the byssus threads) and algae were searched for recruits by 2 people. The first agitated the mussels and algae in water using a sieve (mesh size: $<0.5 \mathrm{~mm}$ ) to release recruits, and also searched them in detail, while the second person went through the samples again using a dissecting microscope. The numbers of adults and recruits within each sample were counted and their shell lengths measured. Vernier calipers were used for adult mussels and larger recruits (0.1 mm precision), and a dissecting microscope with an eye-piece micrometer was used for smaller recruits $(0.01 \mathrm{~mm}$ precision). The definition of recruits $(0.51$ to $10.0 \mathrm{~mm}$ ) complies with other studies of recruitment of P. perna (e.g. Harris et al. 1998, Lawrie \& McQuaid 2001). A huge proportion of $P$. perna mortality occurs before mussels have reached ca. $10 \mathrm{~mm}$ in length (post-settlement mortality), i.e. densities decrease dramatically until that size (S. Kaehler unpubl. data). We further divided recruits into late plantigrades ( 0.51 to $3.50 \mathrm{~mm}$ shell length) and larger recruits (3.51 to $10.0 \mathrm{~mm}$ ), based on measurements and morphology of laboratory reared $P$. perna and the maximum size of plantigrades found on artificial substrata (Lasiak \& Barnard 1995). The vast majority of settlers found on artificial substrata sampled daily are early plantigrades $(<0.5 \mathrm{~mm}$; F. Porri unpubl. data). The biomass of algae (G. pristoides) was estimated for each quadrat sample.

We did not take into account the effect of architectural complexity on the spatial heterogeneity in the distribution of adults and recruits because the different sizes of mussels themselves influence surface complexity, confounding these 2 factors. Moreover, Lawrie \& McQuaid (2001) found no evidence for a relationship between architectural complexity and recruitment.

Data analysis. Pattern of distribution using semivariogram analysis: To describe the spatial variability in the distribution of mussel recruits, adult mussels and algae at different local scales (30 different lags between samples ranging from 0.35 to $10.5 \mathrm{~m}$ ), we used semivariogram analysis, a geostatistical method estimating spatial dependence of a variable (Isaaks \& Srivastava 1989, Dale 2000). The semivariance $\left(Y_{h}\right)$ was estimated as:

$$
Y_{h}=1 /\left(2 N_{h}\right) \sum_{i=1}^{N-h}\left(Z_{i+h}-Z_{i}\right)^{2}
$$

where $N$ is the total number of data points; $N_{h}$ is the number of pairs of data points separated by the distance or lag $h_{i} Z_{i}$ and $Z_{i+h}$ are the values of a variable (e.g. density of mussels) at points $i$ and $i+h$ (Burrough 1983, Palmer 1988, Schmid 2000). Fractal scaling 
analysis was applied to estimate heterogeneity of spatial distributions over the range of scales. This technique has been shown to be useful for studying spatial heterogeneity in mussel beds at local scales (Kostylev $\&$ Erlandsson 2001). The fractal dimension (D) was calculated from the double-logarithmic semivariogram, (which is a plot of $Y_{h}$ vs $h$ ) as:

$$
D=(4-m) / 2
$$

where $m$ is the absolute slope of the regression line (see e.g. Burrough 1983, Schmid 2000). Fractal dimension $(D)$ is a non-integer measure of heterogeneity, with higher heterogeneity giving a flatter slope of the regression line in the semivariogram and higher values of $D$. $D$ varies between 1 and 2, where a value closer to 1 indicates persistent behaviour or a trend-like distribution (e.g. a gradient or regular patches), while a $D$ value closer to 2 indicates anti-persistent behaviour or a more patchy distribution (Feder 1988, Kostylev \& Erlandsson 2001). Simulations of distributions of intertidal organisms show that random distribution patterns have $D$ values between 1.97 and 2 (J. Erlandsson unpubl. data).

Lags (h) up to half of the transect length were included in the regression analysis of the semivariogram. Semivariances do not represent variation between all data points at lags larger than half of the transect length (Palmer 1988, Kostylev 1996, Schmid 2000, Kostylev \& Erlandsson 2001), because at each successive larger scale the number of pairs of points decreases by 1 (from 59 pairs at lag $0.35 \mathrm{~m}$ to 30 pairs at lag $10.5 \mathrm{~m})$.

Pattern of relationships: The relationships between spatial heterogeneity $(D)$ of adult mussel distribution and of both late plantigrades and larger recruits were tested in linear regression analyses, where each transect provided 1 datum point.

To describe the relationships between the distributions of mussel recruits, adult mussels and algae at different spatial scales (30 different lags ranging from 0.35 to $10.5 \mathrm{~m}$ ), we used cross-semivariogram analysis, which is related to semivariogram analysis (Dale 2000). The cross-semivariance $\left(Y_{h}\right)$ was estimated as:

$$
Y_{h}=1 /\left(2 N_{h}\right) \sum_{i=1}^{N-h}\left(X_{i+h}-X_{i}\right)\left(Z_{i+h}-Z_{i}\right)
$$

where $N$ is the total number of data points; $N_{h}$ is the number of pairs of data points separated by the distance or $\operatorname{lag} h_{i} X_{i}$ and $X_{i+h}$, and $Z_{i}$ and $Z_{i+h}$ are the values of 2 different variables (e.g. density of recruits and density of adults) at points $i$ and $i+h$.

A positive cross-semivariance value at a certain lag indicates a positive relationship between variables at that scale and a negative value a negative relationship. Cross-semivariance values around 0 indicate no rela- tionship between variables at that range of scales. Thus, cross-semivariograms can help to describe whether a relationship is stronger at certain scales, and exhibits spatial trends. Negative or positive relationships may thus increase over certain scales showing spatial dependence, which may be estimated in the same way as in semivariograms (see above and below sections). The distributions of pairs of variables along each transect were randomized 1000 times and crosssemivariance values calculated at each scale for each random permutation (see Quinn \& Keough 2002 for information about random permutation tests). Each randomized value was then compared with the appropriate observed cross-semivariance value. Thus, we calculated the probability that each observed crosssemivariance value was so high (positive relationship) or so low (negative relationship) by chance alone, and applied an alpha level of 0.05. Since spatial dependence of relationships between variables makes statistical significance tests speculative (Dale 2000), negative or positive relationships are referred to as strong rather than significant in such cases.

Detection of scaling regions: From either a semivariogram or a cross-semivariogram, natural multiple scaling regions (within which variance changes monotonically with changes in scale) can be detected in the distribution. Fractal dimension can be estimated from a double-logarithmic semivariogram, in which there is self-similarity within ( $D$ is the same) but different fractal dimensions between scaling regions. The spatial structure can be estimated within each scaling region. To detect significant scaling regions, a 3-step procedure was followed for each double-logarithmic semivariogram and nonlogarithmic cross-semivariogram: (1) residual analysis, (2) regression analyses of the different slopes, and (3) $t$-tests comparing different slopes.

(1) Analysis of patterns among residuals (i.e. estimated differences between observed data points and the fitted regression line) was done to distinguish partial regression lines with different slopes and to determine the scale where the break between them occurred. Starting with the whole range of scales, the maximum positive or negative value (opposite sign to the first point value) of residual data was considered to correspond to a transition between scaling regions (see Glejser 1969, Kostylev \& Erlandsson 2001). The same analysis was repeated at the range of scales following a scaling break until all potential partial regressions had been distinguished. (2) Linear regression analysis was conducted for each region and a statistically significant slope suggested that partial regressions at the distinguished scales should be considered. (3) As a last step in the detection of real scaling regions, slopes of significant partial regressions were tested against each other in $t$-tests in order to eliminate possible redun- 
Table 1. Perna perna. Regression exponents of the double-logarithmic semivariograms, and fractal dimensions $(D)$ for the different spatial scales of distribution of adult density on the different transects and shores. WB = Waterloo Bay, RP $=$ Riet Point, PA $=$ Port Alfred; Spat dep = spatial dependence. Analyses significant at $\mathrm{p}<0.05$ in bold, and at $\mathrm{p}<0.10$ in italics. Multiple scaling regions in WB and RP mid-zones are indicated by * and \#, respectively. df: 28 if not otherwise stated

\begin{tabular}{|c|c|c|c|c|c|c|c|c|}
\hline & Transect & Scale (m) (df) & Slope & SE & $\mathrm{R}^{2}$ & $\mathrm{p}$ & $D$ & Spatial pattern \\
\hline \multirow[t]{5}{*}{ Adult mussels } & WB mid & $0.35-10.5$ & 0.042 & 0.180 & 0.039 & 0.29 & 1.979 & Spat dep* \\
\hline & RP mid & $0.35-10.5$ & 0.463 & 0.139 & 0.892 & $<0.001$ & 1.769 & Spat dep\# \\
\hline & RP upper & $0.35-10.5$ & 0.116 & 0.188 & 0.222 & 0.009 & 1.942 & Spat dep \\
\hline & PA mid & $0.35-10.5$ & 0.177 & 0.133 & 0.572 & $<0.001$ & 1.911 & Spat dep \\
\hline & PA upper & $0.35-10.5$ & 0.112 & 0.136 & 0.339 & $<0.001$ & 1.944 & Spat dep \\
\hline \multirow[t]{4}{*}{ Scaling regions } & ${ }^{*} \mathrm{WB}$ mid & $\begin{array}{c}0.35-4.9(12) \\
5.25-10.5(14)\end{array}$ & $\begin{array}{r}0.249 \\
-0.333\end{array}$ & $\begin{array}{l}0.074 \\
0.138\end{array}$ & $\begin{array}{l}0.881 \\
0.230\end{array}$ & $\begin{array}{r}<\mathbf{0 . 0 0 1} \\
0.060\end{array}$ & $\begin{array}{l}1.876 \\
1.834\end{array}$ & $\begin{array}{l}\text { Patchy } \\
\text { Patchy }\end{array}$ \\
\hline & \#RP mid & $0.35-3.5(8)$ & 0.227 & 0.084 & 0.815 & $<0.001$ & 1.886 & Patchy \\
\hline & & $3.85-9.1(14)$ & 0.752 & 0.054 & 0.937 & $<0.001$ & 1.624 & $<$ Patchy \\
\hline & & $9.45-10.5(2)$ & -1.998 & 0.039 & 0.892 & 0.055 & 1.001 & Trend \\
\hline
\end{tabular}

dancy. If slopes of adjacent regressions were significantly different, then the scaling regions were considered valid. Since this procedure of partial regression analyses of a semivariogram or cross-semivariogram may include multiple tests, significance was estimated using the Bonferroni correction.

\section{RESULTS}

\section{Adult mussel distribution}

The semivariograms of the density of adult mussels showed that all transects revealed spatial dependence (Table 1, Fig. 1). Waterloo Bay mid-zone exhibited 2 scaling regions, both indicating patchy mussel distribution (Table 1, Fig. 1). Riet Point mid-zone showed lower heterogeneity than the other transects, and exhibited 3 scaling regions: the 1st exhibiting patchy distribution at smaller scales, the 2 nd being less patchy at larger scales, and the 3rd showing a clear trend in the distribution of mussels at the largest scales (Table 1, Fig. 1). Riet Point upper zone did not show significant multiple scaling regions, but from the semivariogram one can see a random pattern of mussel distribution up to ca. 5 to $6 \mathrm{~m}$ lags, and a clear trend at larger scales (Table 1, Fig. 1). Port Alfred mid- and upper zones exhibited no multiple scaling regions and adult mussel distribution was heterogeneous (Table 1, Fig. 1).

\section{Mussel recruit distribution}

Generally, the density of combined recruits (late plantigrades plus larger recruits) revealed no spatial structure, except for Riet Point mid-zone which showed lower heterogeneity $(1.80<D<1.86)$ and strong spatial dependence in the distribution of total recruits, as well as of late plantigrades and larger recruits separately (Table 2, Fig. 2). Semivariograms for the other transects showed that larger recruits exhibited clearer spatial structure (stronger spatial dependence) than late plantigrades and total number of recruits (Table 2, Fig. 2). Thus, the distribution of larger recruits resembled that of adults more closely than the distribution of late plantigrades and combined recruits did. Larger recruit density showed lower fractal dimensions (Waterloo Bay mid-zone: $D<1.92$ on the 2 scaling regions; Riet Point upper zone and Port Alfred mid- and upper zones: $1.94 \leq D \leq 1.97$ ), while late plantigrades and combined recruits mainly showed random patterns ( $D \geq 1.97$; Table 2, Fig. 2). Similar parallels can be seen in Fig. 3. This shows a significant positive relationship between the spatial heterogeneity $(D)$ of adult density and of larger recruit density, with no clear relationship between $D$ of adult density and $D$ of late plantigrade density. In the 2 transects that showed multiple scaling regions (Waterloo Bay and Riet Point mid-zone), the distribution of larger recruits was more heterogeneous at smaller scales than adult distribution. This was especially so at Riet Point mid-zone (Waterloo Bay mid-zone: $D=1.92 \mathrm{com}-$ pared to $D=1.88$; Riet Point mid-zone: $D=1.96 \mathrm{com}$ pared to $D=1.89$ ).

\section{Algal distribution}

The distribution of algae showed spatial dependence in Waterloo Bay mid-zone, and in Riet Point mid- and upper zones (Table 3). However, spatial heterogeneity was still high in Waterloo Bay mid-zone and Riet Point upper zone, while Riet Point mid-zone showed less heterogeneity in the 3 scaling regions present (Table 3). Port Alfred mid- and upper zones showed spatial independence and high fractal dimensions in the distribution of algae (Table 3), but the abundance of Gelidium pristoides was very low at these transects. 

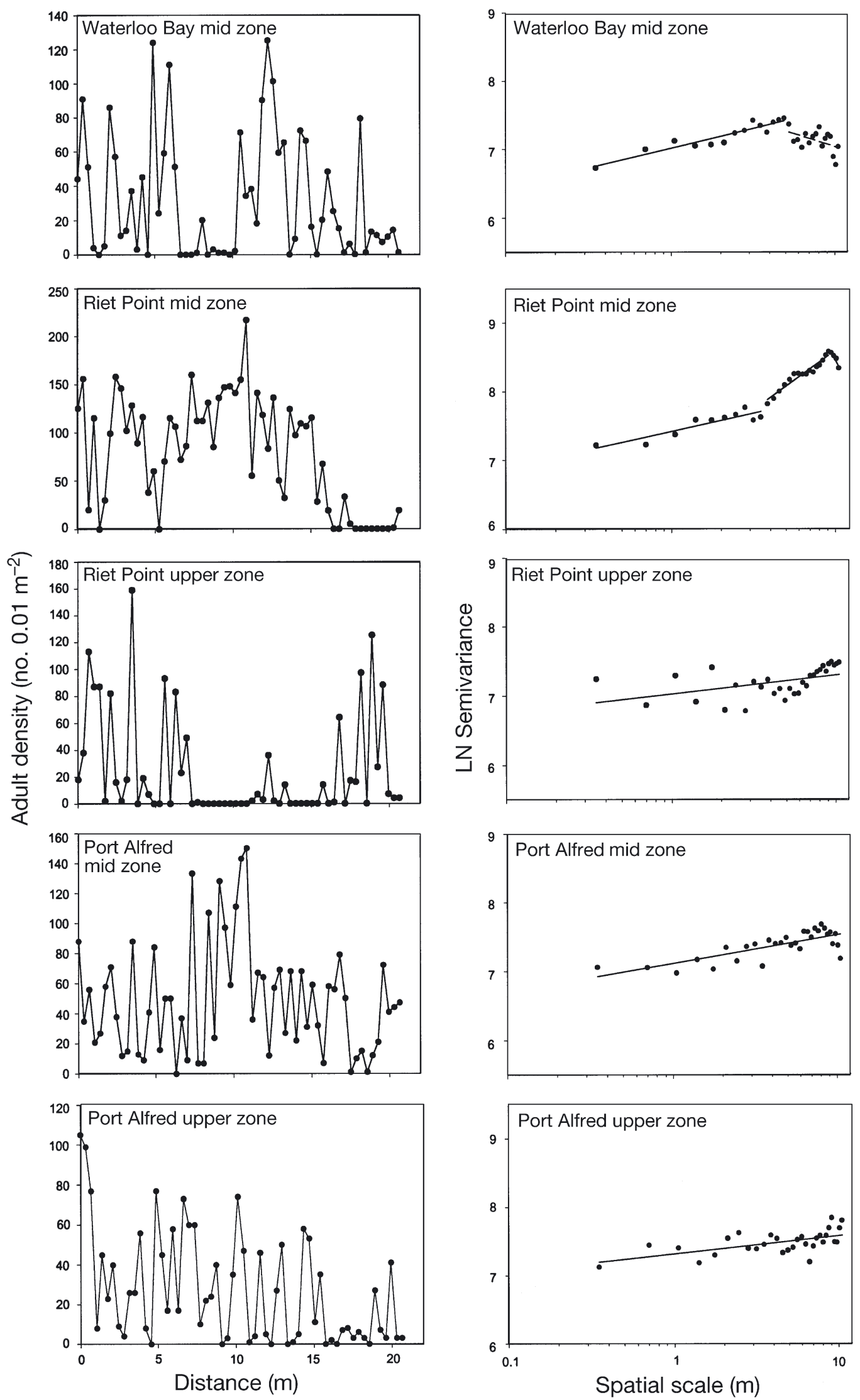

Fig. 1. Perna perna. Distribution of adult mussel density at the different transects, with corresponding semivariograms. Solid regression lines indicate significant scaling regions at $\mathrm{p}<0.05$, and dashed lines (2nd scaling region of Waterloo Bay and 3rd scaling region of Riet Point mid zone) at $\mathrm{p}<0.10$. See Table 1 

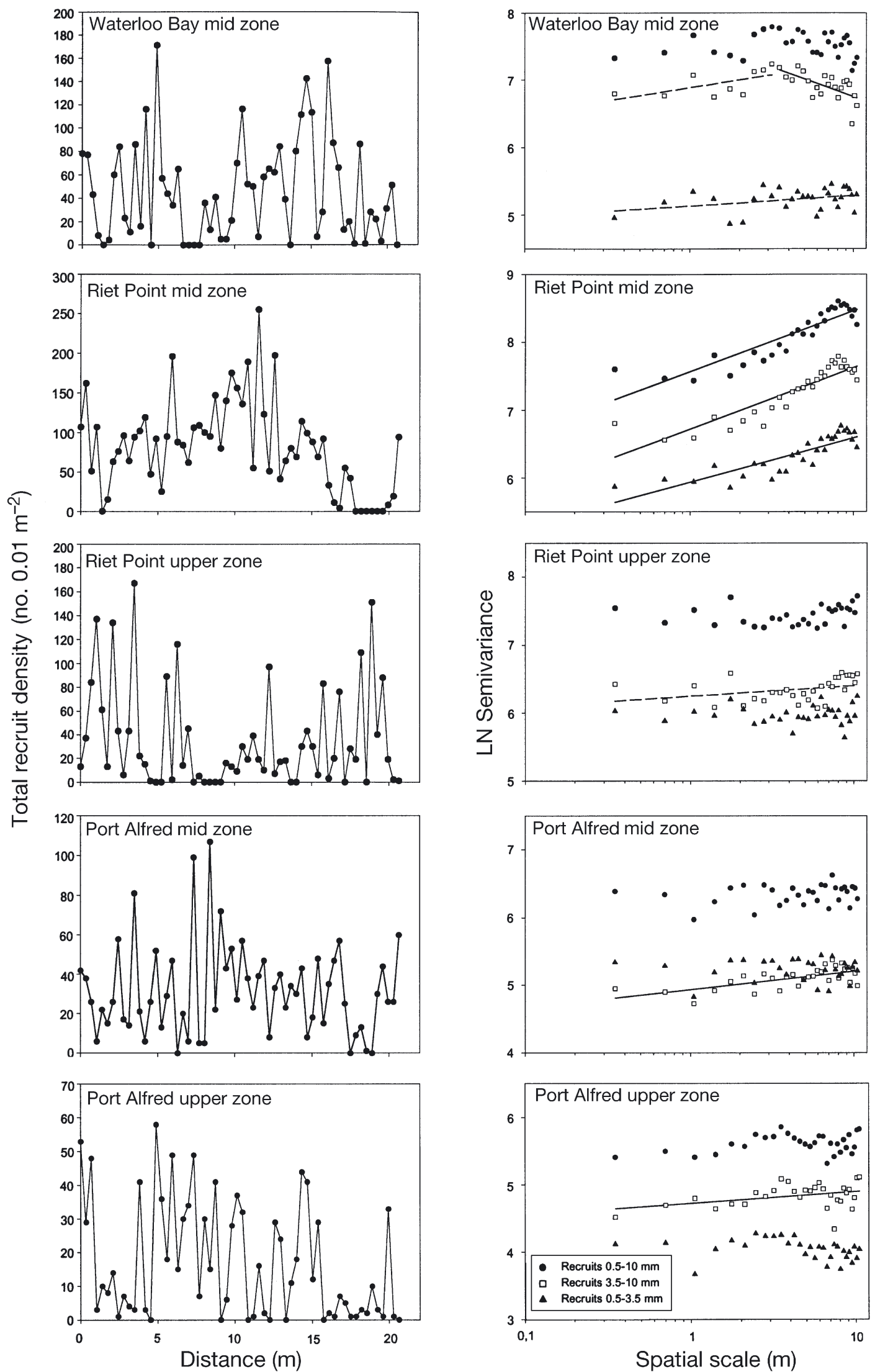

Fig. 2. Perna perna. Distribution of density of total number of recruits (late plantigrades and larger recruits combined) at the different transects, with semivariograms shown for total recruit density, larger recruits $(3.51-10.0 \mathrm{~mm})$, and late plantigrades $(0.51-3.50 \mathrm{~mm})$. Solid regression lines indicate significant scaling regions at $\mathrm{p}<0.05$, and dashed lines at $\mathrm{p}<0.10$. See Table 2 
Table 2. Perna perna. Regression exponents of the double-logarithmic semivariograms, and fractal dimensions $(D)$ for the different spatial scales of distribution of mussel recruits (all recruits: 0.51-10 mm; late plantigrades: 0.51-3.5 mm; larger recruits: 3.51-10 mm) on the different transects and shores. $\mathrm{WB}=$ Waterloo Bay, RP $=$ Riet Point, PA = Port Alfred; Spat dep = spatial dependence, Spat indep = spatial independence. Analyses significant at $p<0.05$ in bold, and at $p<0.10$ in italics. Multiple scaling regions in the distribution of larger recruits in WB mid zone are indicated by ${ }^{*}$. df: 28 if not otherwise stated

\begin{tabular}{|c|c|c|c|c|c|c|c|c|}
\hline & Transect & Scale (m) (df) & Slope & $\mathrm{SE}$ & $\mathrm{R}^{2}$ & $\mathrm{p}$ & $D$ & Spatial pattern \\
\hline \multirow[t]{5}{*}{ All recruits } & WB mid & $0.35-10.5$ & 0.004 & 0.181 & 0.0004 & 0.91 & 1.998 & Spat indep \\
\hline & RP mid & $0.35-10.5$ & 0.389 & 0.169 & 0.799 & $<0.001$ & 1.806 & Spat dep \\
\hline & RP upper & $0.35-10.5$ & 0.032 & 0.139 & 0.039 & 0.30 & 1.984 & Spat indep \\
\hline & PA mid & $0.35-10.5$ & 0.034 & 0.147 & 0.039 & 0.30 & 1.983 & Spat indep \\
\hline & PA upper & $0.35-10.5$ & 0.050 & 0.134 & 0.095 & 0.10 & 1.975 & Spat indep \\
\hline \multirow[t]{5}{*}{ Late plantigrades } & WB mid & $0.35-10.5$ & 0.066 & 0.156 & 0.118 & 0.063 & 1.967 & Spat dep \\
\hline & RP mid & $0.35-10.5$ & 0.285 & 0.151 & 0.727 & $<0.001$ & 1.858 & Spat dep \\
\hline & RP upper & $0.35-10.5$ & -0.001 & 0.140 & $5 \times 10^{-5}$ & 0.97 & 1.999 & Spat indep \\
\hline & PA mid & $0.35-10.5$ & -0.006 & 0.165 & 0.001 & 0.87 & 1.997 & Spat indep \\
\hline & PA upper & $0.35-10.5$ & -0.049 & 0.150 & 0.074 & 0.15 & 1.975 & Spat indep \\
\hline \multirow[t]{5}{*}{ Larger recruits } & WB mid & $0.35-10.5$ & -0.025 & 0.198 & 0.012 & 0.56 & 1.987 & Spat dep* \\
\hline & RP mid & $0.35-10.5$ & 0.392 & 0.171 & 0.798 & $<0.001$ & 1.804 & Spat dep \\
\hline & RP upper & $0.35-10.5$ & 0.067 & 0.161 & 0.114 & 0.068 & 1.967 & Spat dep \\
\hline & PA mid & $0.35-10.5$ & 0.117 & 0.117 & 0.426 & $<0.001$ & 1.942 & Spat dep \\
\hline & PA upper & $0.35-10.5$ & 0.076 & 0.166 & 0.136 & 0.045 & 1.962 & Spat dep \\
\hline \multicolumn{9}{|l|}{${ }^{*}$ Scaling regions } \\
\hline \multirow[t]{2}{*}{ Larger recruits } & WB mid & $0.35-3.15(7)$ & 0.167 & 0.163 & 0.383 & 0.074 & 1.916 & Patchy \\
\hline & & $3.5-10.5$ (19) & -0.379 & 0.158 & 0.401 & 0.002 & 1.810 & Patchy \\
\hline
\end{tabular}
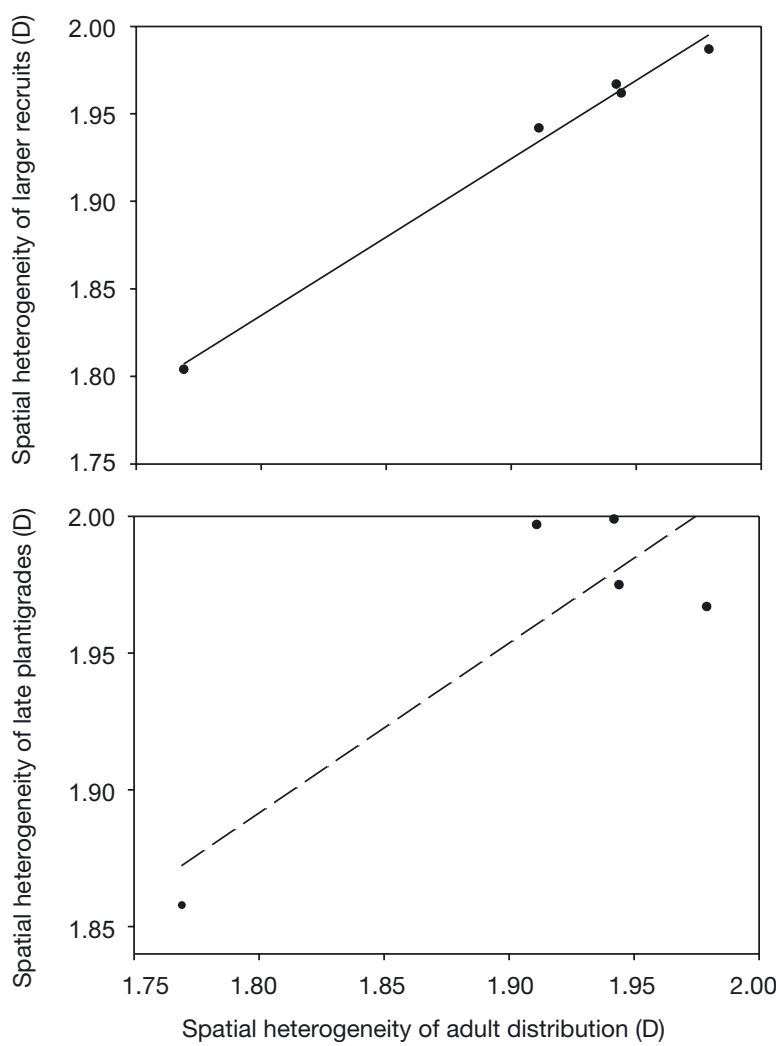

Fig. 3. Perna perna. Linear regression between spatial heterogeneity $(D)$ of adult mussel distribution and $D$ of larger recruits $\left(\mathrm{r}^{2}=0.99, \mathrm{n}=5\right.$; Bonferroni-corrected $\mathrm{p}(\mathrm{B})<0.001$; solid regression line) and late plantigrades $\left(\mathrm{r}^{2}=0.76, \mathrm{n}=5, \mathrm{p}(\mathrm{B})=\right.$ 0.11 ; dashed regression line). Each transect is a data point

\section{Pattern of relationships between recruits and adult mussels}

Cross-semivariograms revealed that density of both late plantigrades and larger recruits exhibited strong positive relationships with density of adult mussels at all transects and at different scales (Table 4, Fig. 4). However, larger recruits were more related to adults than late plantigrades were at all transects. At each scale, cross-semivariance values were higher for larger recruits vs adults than for late plantigrades vs adults (Fig. 4). Furthermore, the scaling pattern of the crosssemivariograms of larger recruits vs adults followed the pattern of semivariograms of adults better (scaling breaks and slopes were similar) than the pattern for late plantigrades vs adults did (Figs. 1 \& 4). All relationships between recruits and adults were weaker at Port Alfred transects than the other transects (Fig. 4). In addition, the relationship between late plantigrades and adult mussels showed spatial independence in both zones at Port Alfred, while all other recruit/adult relationships at all other transects showed spatial dependence, often exhibiting increasing positive relationship with larger scales (Table 4, Fig. 4).

\section{Pattern of relationships between recruits and algae}

The relationship between adult density of Perna perna and biomass of Gelidium pristoides was signifi- 
Table 3. Gelidium pristoides. Regression exponents of the double-logarithmic semivariograms, and fractal dimensions $(D)$ for the different spatial scales of distribution of the alga on the different transects and shores. WB $=$ Waterloo Bay, RP $=\mathrm{Riet}$ Point, $\mathrm{PA}=$ Port Alfred; Spat dep = spatial dependence, Spat indep = spatial independence. Analyses significant at $p<0.05$ in bold, and at $\mathrm{p}<0.10$ in italics. Multiple scaling regions in RP mid-zone are indicated by ${ }^{*}$. df: 28 if not otherwise stated

\begin{tabular}{|llccccccc|}
\hline & Transect & Scale (m) (df) & Slope & SE & $\mathrm{R}^{2}$ & $\mathrm{p}$ & $D$ & Spatial pattern \\
\hline Algae & WB mid & $0.35-10.5$ & 0.140 & 0.191 & 0.288 & $\mathbf{0 . 0 0 2}$ & 1.930 & Spat dep \\
& RP mid & $0.35-10.5$ & 0.031 & 0.184 & 0.020 & 0.45 & 1.985 & Spat dep* \\
& RP upper & $0.35-10.5$ & 0.147 & 0.131 & 0.558 & $<\mathbf{0 . 0 0 1}$ & 1.927 & Spat dep \\
& PA mid & $0.35-10.5$ & -0.066 & 0.179 & 0.094 & 0.10 & 1.967 & Spat indep \\
& PA upper & $0.35-10.5$ & 0.040 & 0.230 & 0.022 & 0.44 & 1.980 & Spat indep \\
Scaling regions & * RP mid & $0.35-2.1(4)$ & 0.374 & 0.123 & 0.835 & $\mathbf{0 . 0 1 1}$ & 1.813 & Patchy \\
& & $2.45-6.65(11)$ & -0.431 & 0.128 & 0.559 & $\mathbf{0 . 0 0 3}$ & 1.784 & Patchy \\
& & $7-10.5(9)$ & 0.532 & 0.104 & 0.342 & 0.059 & 1.734 & $<$ Patchy \\
\hline
\end{tabular}

cantly negative at many small and large local scales (Table 4, Fig. 5, cross-semivariance values $<0$ ). In contrast, the relationship between total number of mussel recruits (late plantigrades and larger recruits combined) and algal biomass was mainly mixed, i.e. positive, negative and no relationship at different scales (Table 4, Fig. 5). The results of random permutation tests of combined recruits vs algae are not indicated as this mixture of significant negative and positive values made the graphs very confusing. However, taking the 2 size classes of recruits separately gives a clearer pattern. The relationship between density of larger recruits and algal biomass tended to be more negative (cross-semivariance values were significantly negative at similar scales as for adults vs algae), while the relationship between late plantigrades and algae tended to be more positive (significantly positive values at different lags in 3 transects; Table 4, Fig. 5). The main exception was Riet Point mid-zone where both relationships were mixed. The relationship between algae and both size classes of recruits showed spatial independence in Port Alfred mid- and upper zones (except late plantigrades vs algae in Port Alfred upper zone), and spatial dependence at the other transects (Table 4, Fig. 5).

\section{DISCUSSION}

Studies of recruitment variability of mussels have found no consistent spatial patterns at local withinshore scales (e.g. Harris et al. 1998, Lawrie \& McQuaid 2001), suggesting stochastic patterns in recruitment. Thus, the important questions are whether the high recruitment variability of Perna perna at local scales exhibits spatial structure (as does percent cover of $P$. perna) and whether one can explain this heterogeneity. The present study found, in general, no spatial structure in the distribution of total number of recruits (both size classes combined) over a range of local scales. That is, 4 out of 5 transects exhibited spatial independence, i.e. a stochastic pattern (Fig. 2). However, Riet Point mid-zone exhibited clear spatial dependence and much lower fractal dimension in the distribution of recruits (for all size classes: $1.80<D<$ 1.86) compared to the other transects. This echoes the strong spatial dependence and lower fractal dimensions in the distributions of adult mussel density (Table 1, Fig. 1), mussel cover and topography (J. Erlandsson unpubl. data) in Riet Point mid-zone. The other transects showed higher spatial heterogeneity in the distribution of adults, even though they all

Table 4. Perna perna and Gelidium pristoides. Summary of the general relationships between distributions of adult mussels, algae and mussel recruits (all recruits: $0.51-10 \mathrm{~mm}$; late plantigrades: $0.51-3.5 \mathrm{~mm}$; larger recruits $3.51-10 \mathrm{~mm}$ ) examined by cross-semivariograms at different scales (see Figs. 4, 5 and 'Results'). $\mathrm{WB}=$ Waterloo Bay; RP $=$ Riet Point; PA $=$ Port Alfred; Spat Dep = spatial dependence $;$ Spat Indep = spatial independence + +: positive relationship; - : negative relationship; $0:$ no relationship $;+/ 0 /-$ : variable relationship

\begin{tabular}{|c|c|c|c|c|c|}
\hline \multirow[t]{3}{*}{ Variable } & \multirow{3}{*}{$\begin{array}{l}\text { WB } \\
\text { Mid }\end{array}$} & \multirow{2}{*}{\multicolumn{3}{|c|}{-Spatial pattern and relationship }} & \multirow[b]{3}{*}{ Upper } \\
\hline & & \multirow{2}{*}{$\frac{}{\text { Mid }}$ R } & & & \\
\hline & & & Upper & Mid & \\
\hline Adults vs algae & Spat indep - & Spat dep - & Spat dep - & Spat indep - & Spat \\
\hline All recruits vs adults & Spat dep + & Spat dep + & Spat dep + & Spat dep+ & Spat dep + \\
\hline Late plantigrades vs adults & Spat dep + & Spat dep + & Spat dep + & Spat indep + & Spat indep + \\
\hline Larger recruits vs adults & Spat dep + & Spat dep + & Spat dep + & Spat dep + & Spat dep + \\
\hline All recruits vs algae & Spat indep +/0/- & Spat dep +/0/- & Spat dep +/0/- & Spat indep - & Spat indep $+/ 0 /-$ \\
\hline Late plantigrades vs algae & Spat dep + & Spat dep +/0/- & Spat dep + & Spat indep +/0/- & Spat dep + \\
\hline Larger recruits vs algae & Spat dep - & Spat dep +/0/- & Spat dep - & Spat indep - & Spat indep - \\
\hline
\end{tabular}


exhibited spatial dependence (Fig. 1). The spatial structure of adult abundance was similar to that of mussel cover distribution (J. Erlandsson unpubl. data), presumably because these mussel beds form monolayers. The difference in the spatial structure of distributions between Riet Point mid-zone and the other transects indicates that there is spatial structure in the distribution of total recruit density only if there is a clear spatial structure of adult mussel distribution.

However, if one considers the distribution of late plantigrades ( 0.5 to $3.5 \mathrm{~mm}$ ) and larger recruits (3.5 to $10 \mathrm{~mm}$ ) separately, a more interesting picture emerges. Larger recruits exhibited spatial dependence in their distribution at all transects, revealing a spatial structure that corresponded more to that of adult distribution (Figs. 1 to 3). Density of larger recruits showed higher spatial heterogeneity when adult distribution showed higher spatial heterogeneity (Fig. 3). In con-

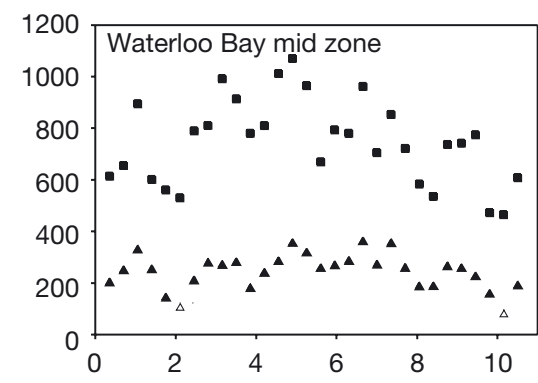

- Large recruits vs adults

- Late plantigrades vs adults
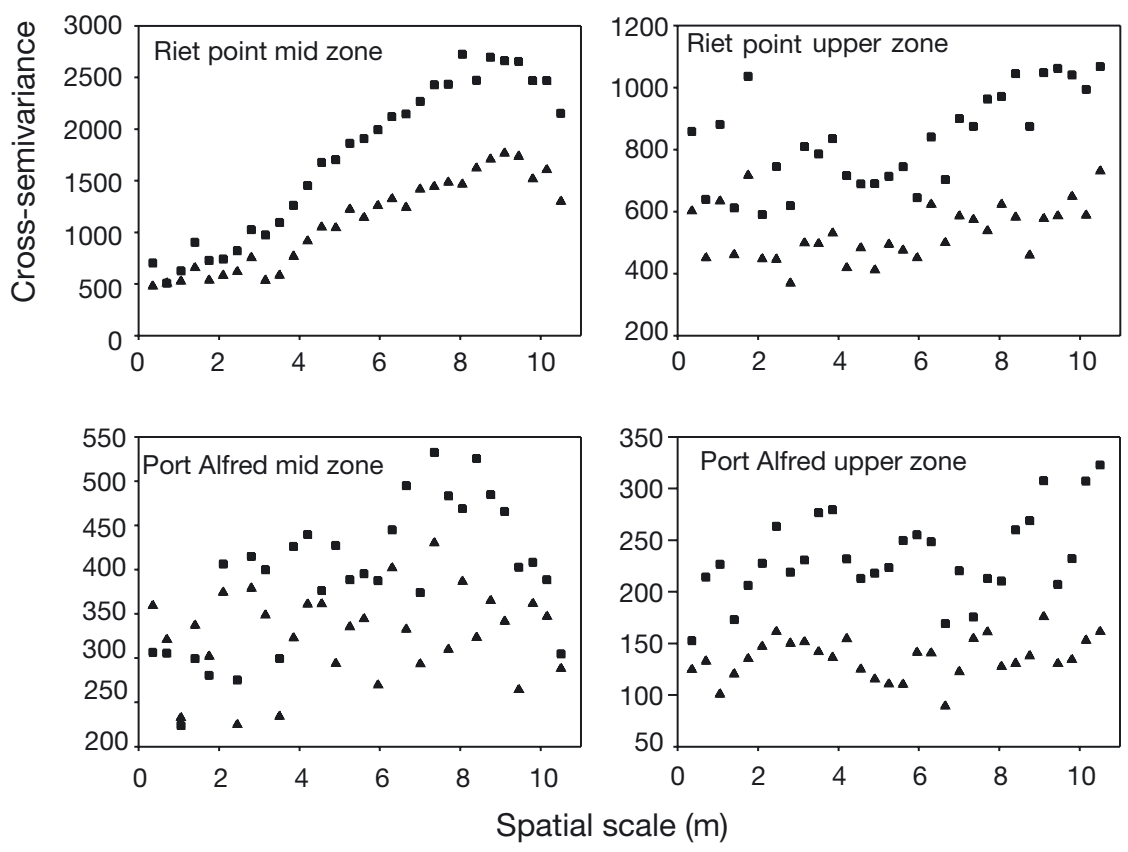

Fig. 4. Perna perna. Cross-semivariograms of the relationships between the densities of adults and larger recruits $(3.51-10.0 \mathrm{~mm})$, and adults and late plantigrades $(0.51-3.50 \mathrm{~mm})$ at the different transects. Positive relationships (indicated by the cross-semivariance values), significant at $\mathrm{p}<0.05$, as estimated by random permutation tests (1000 permutations), are shown as closed symbols at each lag. Non-significant relationships are shown as open symbols trast, late plantigrade distribution mainly showed spatial independence (random distribution pattern), with a fractal dimension between 1.97 and 2 at most transects (Table. 2, Fig. 2). Density of late plantigrades only exhibited spatial structure similar to that of adult density in Riet Point mid-zone (Figs. 1 \& 2), and consequently there was no clear relationship between spatial heterogeneity of adult and late plantigrade distribution (Fig. 3). Thus, the spatial structure of adult mussels and larger recruits of Perna perna was similar cross a range of local scales. A notable difference, owever, was that the spatial heterogeneity at the (1st scaling region: up to ca. $5 \mathrm{~m}$ ANOVA), both adults and recruits (small and large) showed higher variability at the smallest within-shore scale considered (5 $\mathrm{m}$ lag) than at the larger within-shore scale $(10 \mathrm{~m}$ lag) or the between-shore scale in both mid and upper zones (unpubl. data). This is similar to the findings of other studies of distribution patterns of adult mussels, juveniles and recruits across local to regional scales (Harris et al. 1998, Blanchard \& Bourget 1999, Lawrie \& McQuaid 2001).

The relationship between adults and recruits (both size classes) was strongly positive at all transects and scales (Table 4 , Fig. 4), often showing spatial dependence and increasing with larger local scales (Fig. 4). In contrast, Hewitt et al. (1997) found that in a soft-bottom bivalve, relationships between adults and juveniles at local scales alternated between negative and positive correlations, depending on the lag. McQuaid et al. (2000) also found positive relationships between adults and recruits/juveniles of Perna perna, though $\mathrm{r}^{2}$-values were very low (ca. 0.1). The different results (weak vs strong relationships) between McQuaid et al. (2000) and the present study may be due to different sampling designs (sites pooled vs not pooled; random samples vs sampling along transects) and different size definitions of recruits and adults. A further difference is that in this study, we divided recruits into 2 size classes, and found that the relationship between adults and recruits was stronger for the larger size class at all scales (Fig. 4). This explains why larger recruits showed clearer spatial structure and why this structure was more 

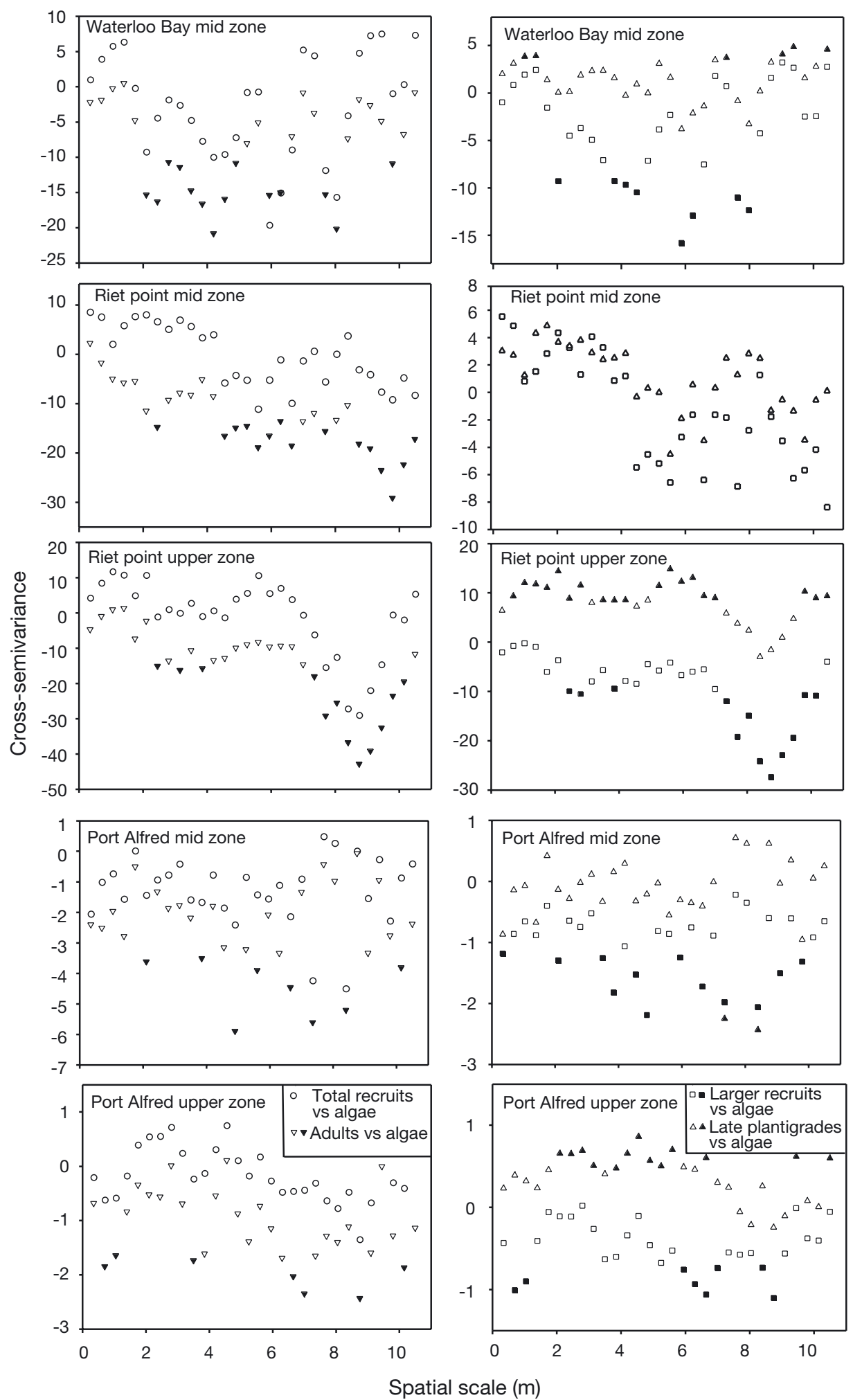

Fig. 5. Perna perna and Gelidium pristoides. Cross-semivariograms of the relationships between: (1) density of adult mussels and algal biomass, (2) total recruit density (late plantigrades and larger recruits combined) and algal biomass, (3) larger mussel recruits (3.51-10.0 mm) and algal biomass, and (4) late plantigrades (0.51-3.50 mm) and algal biomass, at the different transects. Negative or positive relationships (indicated by the cross-semivariance values), significant at $\mathrm{p}<0.05$, as estimated by random permutation tests (1000 permutations), are shown as closed symbols at each lag. Non-significant relationships are shown as open symbols. Results of random permutation tests are not shown for total recruit density vs algal biomass (see 'Results') 
similar to that of adults. Recruits may survive better among established mussel beds. Mussel clumps have been shown to have high structural complexity (Kostylev et al. 1997, Commito \& Rusignuolo 2000), and it has been suggested that density of mussel recruits increases in the lower layers of multi-layered mussel beds, possibly due to increased complexity of the matrix and reduced water flow (Alvarado \& Castilla 1996). However, mussel beds on this coast are mainly monolayered with many recruits of $P$. perna found among the byssus threads, which are often attached directly to the rock surface (e.g. McQuaid et al. 2000, C. McQuaid pers. obs.).

The distribution of Gelidium pristoides biomass showed very high fractal dimensions $(1.93<D<1.99$; except in the 3 scaling regions in Riet Point mid-zone), with spatial independence at Port Alfred transects (where algal biomass was especially low) and spatial dependence at the others (Table 3). This agrees with the distribution pattern of algal cover (J. Erdlandsson unpubl. data). The distributions of adult Perna perna and $G$. pristoides show a clear negative relationship at many scales (Fig. 5; unpubl. data), suggesting competition for space between them, while the relationship between total recruit density and algal biomass varies between positive and negative correlations (Fig. 5). Again, however, the picture is clearer if late plantigrades and larger recruits are analyzed separately. The relationship between larger recruits and algae was mainly negative, while the relationship between late plantigrades and algae was positive at many scales (Fig. 5), with spatial dependence occurring mainly at Riet Point and Waterloo Bay transects (in accord with the distribution pattern of G. pristoides). This suggests that different size classes of mussels show contrasting relationships with $G$. pristoides. Algae may be a suitable habitat for early and late plantigrades to settle and recruit onto (e.g. from a hydrodynamic perspective), but as mussels grow, they may compete for space with G. pristoides. Alternatively, removal of larger recruits from algae will lead to an apparent negative relationship.

Our findings are in agreement with Beckley (1979), who reported that the majority of Perna perna found on Gelidium pristoides in one population were less than $5 \mathrm{~mm}$ in size. Settling mussels may actively choose to settle onto algae, as suggested by Bayne (1964). However, recent work shows that, while settlement of invertebrate larvae may be an active process at mm scales, at scales of $3 \mathrm{~cm}$ or greater, settlement onto arborescent artificial substrata may be a passive process due to hydrodynamics, resulting in higher densities in habitats with greater complexity or surface area (Bourget \& Harvey 1998).

We found that late plantigrades were associated with both Perna perna clumps and the alga Gelidium pris- toides, and this explains why we generally found less spatial structure and higher fractal dimension in their distribution. Lasiak \& Barnard (1995) and Lindsay (1998) found that early and late plantigrades were common among both algae and mussels. As with the latter studies, the present work indicates that, in $P$. perna, direct settlement onto adult mussels is as common as primary settlement onto algae followed by possible secondary settlement onto adult beds, i.e. many larvae do not exhibit primary/secondary settlement. Recruits larger than $3.5 \mathrm{~mm}$, on the other hand, are not associated with G. pristoides (Fig. 5). One explanation for this may be that the spatial structure of larger recruits is similar to that of adults because settlement-associated and post-settlement mortality may structure the distribution.

Even if our data do not support the primary/ secondary settlement hypothesis for Perna perna, mussel larvae that settle onto Gelidium pristoides have the potential to stay there until they have grown to a size of ca. 3.5 to $5 \mathrm{~mm}$. The fate of individual mussels larger than this size is unclear. They may either migrate and settle/recruit secondarily onto adult mussels, or they may die when they grow too big to maintain themselves on algae. The question remains whether settlement of $P$. perna onto algae is wasted. Recruitment and recovery rates of $P$. perna are low compared to other mytilid mussels (Lasiak \& Barnard 1995, J. Erlandsson unpubl. data) and this will be exacerbated by the loss of larvae settling on algae. On the east and south coasts of South Africa, where densities and recruitment of mussels are especially low, the exploitation pressure from local people using $P$. perna as a food source is much greater than on the west coast where mussel recruitment is orders of magnitude higher (Harris et al. 1998). Even if secondary settlement of $P$. perna from algae to mussels does occur, there will be little or no recruitment of mussels on heavily exploited shores (e.g. on the east coast) due to the absence of adult patches. There is the additional threat of commercial harvesting of $G$. pristoides on the south and east coasts (e.g. Branch et al. 1994), which would further reduce effective recruitment rates of $P$. perna. Understanding the fate of plantigrades will therefore be important for managing natural populations of $P$. perna that are subject to exploitation.

Acknowledgements. We are most grateful to N. Ntomboxolo and A. Solbrig-Holland for help in the processing of samples. Thanks are due to P. Pal, F. Porri, S. Kaehler and S. Bownes for help in the field. The manuscript was greatly improved by comments from V. Kostylev, P. Petraitis, W. Froneman and 3 anonymous referees. This study was funded by postdoctoral fellowships (to J.E.) from Hellmuth Hertz Foundation, The Royal Swedish Academy of Sciences, Stint Foundation, Sweden, and Rhodes University, South Africa. 


\section{LITERATURE CITED}

Alvarado JL, Castilla JC (1996) Tridimensional matrices of mussels Perumytilus purpuratus on intertidal platforms with varying wave forces in central Chile. Mar Ecol Prog Ser 133:135-141

André C, Jonsson PR, Lindegarth M (1993) Predation on settling larvae by benthic suspension feeders: the role of hydrodynamics and larval behaviour. Mar Ecol Prog Ser 97:183-192

Bayne BL (1964) Primary and secondary settlement in Mytilus edulis L. (Mollusca). J Anim Ecol 33:513-523

Beckley LE (1979) Primary settlement of Perna perna (L.) on littoral seaweeds on St. Croix Island. S Afr J Zool 14: 171-174

Blanchard D, Bourget E (1999) Scales of coastal heterogeneity: influence on intertidal community structure. Mar Ecol Prog Ser 179:163-173

Booth DJ, Brosnan DM (1995) The role of recruitment dynamics in rocky shore and coral reef fish communities. Adv Ecol Res 26:309-385

Bourget E, Harvey M (1998) Spatial analysis of recruitment of marine invertebrates on arborescent substrata. Biofouling 12:45-55

Branch GM, Griffiths CL, Branch ML, Beckley LE (1994) Two oceans: a guide to the marine life of southern Africa. David Philip Publishers, Cape Town

Burrough PA (1983) Multiscale sources of spatial variation in soil: 1 . The application of fractal concepts to nested levels of soil variation. J Soil Sci 34:577-597

Caley MJ, Carr MH, Hixon MA, Hughes TP, Jones GP, Menge BA (1996) Recruitment and the local dynamics of open marine populations. Annu Rev Ecol Syst 27:477-500

Chiba S, Noda T (2000) Factors maintaining topographyrelated mosaic of barnacle and mussel on a rocky shore. J Mar Biol Assoc UK 80:617-622

Commito JA, Rusignuolo BR (2000) Structural complexity in mussel beds: the fractal geometry of surface topography. J Exp Mar Biol Ecol 255:133-152

Dale MRT (2000) Spatial pattern analysis in plant ecology. Cambridge University Press, Cambridge

Ettema CH, Wardle DA (2002) Spatial soil ecology. Trends Ecol Evol 17:177-183

Feder J (1988) Fractals. Plenum Press, New York

Glejser H (1969) A new test for heteroscedascity. J Am Stat Assoc 64:316-323

Harris JM, Branch GM, Elliott BL, Currie B, Dye A, McQuaid CD, Tomalin BJ, Velasquez C (1998) Spatial and temporal variability in recruitment of intertidal mussels around the coast of southern Africa. S Afr J Zool 33:1-11

Hewitt JE, Legendre P, McArdle BH, Thrush SF, Bellehumeur C, Lawrie SM (1997) Identifying relationships between adult and juvenile bivalves at different spatial scales. J Exp Mar Biol Ecol 216:77-98

Isaaks EH, Srivastava RM (1989) Applied geostatistics. Oxford University Press, New York

Kolasa J, Rollo CD (1991) The heterogeneity of heterogeneity: a glossary. In: Kolasa J, Pickett STA (eds) Ecological heterogeneity. Springer-Verlag, New York, p 1-23

Kostylev V (1996) Spatial heterogeneity and habitat complex-

Editorial responsibility: Roger Hughes (Contributing Editor), Bangor, UK ity affecting marine littoral fauna. PhD thesis, Göteborg University, Göteborg

Kostylev V, Erlandsson J (2001) A fractal approach for detecting spatial hierarchy and structure on mussel beds. Mar Biol 139:497-506

Kostylev V, Erlandsson J, Johannesson K (1997) Microdistribution of the polymorphic snail Littorina saxatilis (Olivi) in a patchy rocky shore habitat. Ophelia 47:1-12

Lasiak TA, Barnard TCE (1995) Recruitment of the brown mussel Perna perna onto natural substrata: a refutation of the primary/secondary settlement hypothesis. Mar Ecol Prog Ser 120:147-153

Lawrie SM, McQuaid CD (2001) Scales of mussel bed complexity: structure, associated biota and recruitment. J Exp Mar Biol Ecol 257:135-161

Legendre P (1993) Spatial autocorrelation: trouble or new paradigm? Ecology 74:1659-1673

Lindsay JR (1998) Effects of zone and wave exposure on population structure and recruitment of the mussel Perna perna in South Africa. MSc thesis, Rhodes University, Grahamstown

McGrath D, King PA, Gosling EM (1988) Evidence for the direct settlement of Mytilus edulis larvae on adult mussel beds. Mar Ecol Prog Ser 47:103-106

McKindsey CW, Bourget E (2000) Explaining mesoscale variation in intertidal mussel community structure. Mar Ecol Prog Ser 205:155-170

McQuaid CD, Lindsay TL (2000) Effect of wave exposure on growth and mortality rates of the mussel Perna perna: bottom-up regulation of intertidal populations. Mar Ecol Prog Ser 206:147-154

McQuaid CD, Lindsay JR, Lindsay TL (2000) Interactive effects of wave exposure and tidal height on population structure of the mussel Perna perna. Mar Biol 137: 925-932

Nielsen KJ, Franz DR (1995) The influence of adult conspecifics and shore level on recruitment of the ribbed mussel Geukensia demissa (Dillwyn). J Exp Mar Biol Ecol 188:89-98

Palmer MW (1988) Fractal geometry: a tool for describing spatial patterns of plant communities. Vegetatio 75:91-102

Petraitis PS (1995) The role of growth in maintaining spatial dominance by mussels (Mytilus edulis). Ecology 76: $1337-1346$

Quinn GP, Keough MJ (2002) Experimental design and data analysis for biologists. Cambridge University Press, Cambridge

Schmid PE (2000) Fractal properties of habitat and patch structure in benthic ecosystems. Adv Ecol Res 30:339-401

Seed R (1969) The ecology of Mytilus edulis L. (Lamellibranchiata) on exposed rocky shores: I. Breeding and settlement. Oecologia 3:277-316

Suchanek TH (1985) Mussels and their rôle in structuring rocky shore communities. In: Moore PG, Seed R (eds) The ecology of rocky coasts. Columbia University Press, New York, p 70-96

Sugihara G, May R (1990) Applications of fractals in ecology. Trends Ecol Evol 5:79-86

Wiens JA (1989) Spatial scaling in ecology. Funct Ecol 3: 385-397

Submitted: May 13, 2003; Accepted: October 28, 2003

Proofs received from author(s): February 11, 2004 